\title{
Transcriptomic analyses reveal the underlying pro-malignant functions of PTHR1 for osteosarcoma via activation of Wnt and angiogenesis pathways
}

\author{
Shenglong $\mathrm{Li}^{1 \dagger}$, Yujin Dong ${ }^{2 \dagger}, \mathrm{Ke} \mathrm{Wang}^{3 \dagger}$, Zhe Wang ${ }^{4}$ and Xiaojing Zhang ${ }^{1 *}$
}

\begin{abstract}
Background: Increasing evidence has indicated parathyroid hormone type 1 receptor (PTHR1) plays important roles for the development and progression of osteosarcoma (OS). However, its function mechanisms remain unclear. The goal of this study was to further illuminate the roles of PTHR1 in OS using microarray data.

Methods: Microarray data were available from the Gene Expression Omnibus database under the accession number GSE46861, including six tumors from mice with PTHR1 knockdown (PTHR1.358) and six tumors from mice with control knockdown (Ren.1309). Differentially expressed genes (DEGs) between PTHR1.358 and Ren.1309 were identified using the LIMMA method, and then, protein-protein interaction (PPI) network was constructed using data from STRING database to screen crucial genes associated with PTHR1. KEGG pathway enrichment analysis was performed to investigate the underlying functions of DEGs using DAVID tool.

Results: A total of 1163 genes were identified as DEGs, including 617 downregulated (Lef1, lymphoid enhancerbinding factor 1) and 546 upregulated genes (Dkk1, Dickkopf-related protein 1). KEGG enrichment analysis indicated upregulated DEGs were involved in Renin-angiotensin system (e.g., Agt, angiotensinogen) and Wnt signaling pathway (e.g., Dkk1), while downregulated DEGs participated in Basal cell carcinoma (e.g., Lef1). A PPI network (534 nodes and 2830 edges) was constructed, in which Agt gene was demonstrated to be the hub gene and its interactive genes (e.g., CCR3, CC chemokine receptor 3; and CCL9, chemokine CC chemokine ligand 9) were inflammation related.

Conclusions: Our present study preliminarily reveals the pro-malignant effects of PTHR1 in OS cells may be mediated by activating Wnt, angiogenesis, and inflammation pathways via changing the expressions of the crucial enriched genes (Dkk1, Lef1, Agt-CCR3, and Agt-CCL9).
\end{abstract}

Keywords: Osteosarcoma, PTHR1, Wht pathway, Angiogenesis, Inflammation

\section{Background}

Osteosarcoma (OS) is the most frequent primary malignant bone tumor developed in the metaphyses of long bones during childhood and adolescence, with an estimated incidence of approximately 3.5 per million $[1,2]$. Despite intensive multiagent chemotherapy and surgical

\footnotetext{
* Correspondence: xiaaojingzhang@hotmail.com

${ }^{\dagger}$ Equal contributors

'Department of Bone and Soft Tissue Tumor Surgery, Cancer Hospital of China Medical University, Liaoning Cancer Hospital \& Institute, 44, Xiaoheyan Road, Dadong District, Shenyang, Liaoning 110042, China

Full list of author information is available at the end of the article
}

resection have dramatically increased the 5-year survival rate to $70 \%$, death still occurs in about $30 \%$ of patients with OS due to recurrence and metastasis (specially to the lung) $[1,2]$. Thus, improving understanding of the mechanisms of OS progression and exploiting underlying strategies for malignancy suppression has justifiably attracted a great deal of attention.

Recently, accumulating evidence has indicated parathyroid hormone type 1 receptor (PTHR1), a G-proteincoupled receptor, may play important roles in the pathogenesis of OS. PTHR1 is found to be highly expressed in 
OS cells and tissues (especially in metastatic or relapsed samples) [3-7]. Over-expression of PHTR1 promotes proliferation, motility, and invasion of OS cells, which can be reversed by shRNA-mediated gene silencing $[3,7$, 8]. Further studies suggest PHTR1 may exert the tumorpromoting effects through being activated by its ligands, including parathyroid hormone (PTH) and parathyroid hormone-related peptide (PTHrP) $[9,10]$. Upon activation by PTH/PTHrP, PTHR1 induces the generation of cyclic AMP (cAMP) from ATP through adenylyl cyclase followed by the release of cAMP-dependent protein kinases [9-11]. Active protein kinases (PKA, PKC, or ERK) move to the nucleus and phosphorylates transcription factors, such as cAMP-response element-binding protein (CREB) and runt-related transcription factor 2 (Runx-2) which ultimately lead to the development of OS through regulating the expression their target genes (TGF-b1, transforming growth factor b1; CTGF, connective tissue growth factor; FGF-2, fibroblast growth factor; HAS2, HA-synthase-2 [3, 12, 13]). However, the functions of PTHR1 in OS remain not fully understood.

The goal of this study was to further illuminate the mechanisms of PTHR1 by analyzing the microarray data of OS [8]. Differentially expressed genes (DEGs) between OS tissues with and without PTHR1 knockdown were identified and then protein-protein interaction (PPI) network was constructed to screen crucial genes associated with PTHR1, which was not performed in the study of Ho et al. [8]. Our studies may provide new insights into the mechanisms of PTHR1 in OS and reveal some potential targets for treatment of OS.

\section{Methods}

\section{Microarray data}

The microarray data of OS were extracted from the Gene Expression Omnibus (GEO) database (http:// www.ncbi.nlm.nih.gov/geo/) under the accession number GSE46861 [8], which contained six tumors with shRNA PTHR1 knockdown and six tumors with shRNA control knockdown. The tumor tissues were obtained from $\mathrm{Balb} / \mathrm{c} \mathrm{nu} / \mathrm{nu}$ mice undergoing mouse OS80 cell line injection into the back flank and grown for 4 weeks. Mouse OS80 was transfected with either renilla luciferase shRNA control (Ren.1309) or a shRNA specific for PTHR1 (PTHR1.358). Thus, PTHR1.358 and Ren.13096 cell samples were used to descript these two groups in the following analysis.

\section{Data normalization and DEG identification}

The raw data (CEL files) downloaded from the Affymetrix Mouse Gene 1.0 ST Array platform GPL6246 were preprocessed and normalized using the Robust Multichip Average (RMA) algorithm [14] as implemented in the Bioconductor R package (http://www.bioconductor.org/ packages/release/bioc/html/affy.html). The DEGs between PTHR1.358 and Ren.13096 cell samples were identified using the Linear Models for Microarray data (LIMMA) method [15] in the Bioconductor $\mathrm{R}$ package (http:// www.bioconductor.org/packages/release/bioc/html/limma. html). After the $t$ test, the $p$ value was corrected with the Benjamini-Hochberg (BH) algorithm [16]. Genes with an adjusted $p<0.05$ and $\mid \operatorname{logFC}$ (fold change) $\mid>0.5$ were considered differentially expressed.

\section{PPI network construction}

To screen crucial genes associated with PTHR1, the DEGs were imported into the PPI data that were collected from acknowledged STRING 10.0 (Search Tool for the Retrieval of Interacting Genes; http://stringdb.org/) database [17]. The PPIs with combined scores $>0.7$ were selected to construct the PPI network which was visualized using Cytoscape software 2.8 (www.cytoscape.org/) [18]. Three topological properties, including degree [the number of interactions per node (protein)], betweenness (the number of shortest paths that pass through each node), and closeness centrality (the average length of the shortest paths to access all other proteins in the network) were calculated using the CytoNCA plugin in cytoscape software (http://apps.cytoscape.org/ apps/cytonca) [19] to rank the nodes in the PPI network. In addition, the Molecular Complex Detection (MCODE) plugin of Cytoscape software was also employed to identify functionally related and highly interconnected clusters from the PPI network with a degree cutoff of 2, node score cutoff of 0.2 , k-core of 2 , and maximum depth of 100 (http://baderlab.org/Software/MCODE) [20]. Significant modules were identified with MCODE score $\geq 4$ and nodes $\geq 6$.

\section{Function enrichment analysis}

Gene ontology (GO) and Kyoto encyclopedia of genes and genomes (KEGG) pathway enrichment analyses were performed to investigate the underlying functions of all DEGs and the DEGs in PPI network using The Database for Annotation, Visualization and Integrated Discovery (DAVID) 6.8 online tool (http://david.abcc.ncifcrf.gov). A modified Fisher Exact $p$ value $<0.05$ was chosen as the cutoff point for GO and KEGG analyses.

\section{Results}

\section{Identification of DEGs}

After data normalization, 1163 genes were identified as DEGs between PTHR1.358 and Ren.13096 cell samples based on the threshold of adjusted $p<0.05$ and $|\log \mathrm{FC}|>0.5$, including 617 downregulated (such as Lef1, lymphoid enhancer-binding factor 1) and 546 upregulated genes (such as Dkk1, Dickkopf-related protein 1) (Table 1). Furthermore, PTHR1 was also found to be 
significantly downregulated ( $\log \mathrm{FC}=-0.6919$, adjusted $p$ value $=0.0002$ ), indirectly demonstrating the knockdown model had been established successfully.

\section{Function enrichment analysis}

The above differential genes were subjected to the online tool DAVID for function enrichment analysis with the mouse genome as background and $p<0.05$ as the cutoff point. As a result, 24 KEGG pathways were enriched for upregulated DEGs, including Renin-angiotensin system (e.g., Agt, angiotensinogen), Renin secretion (e.g., Agt), and Wnt signaling pathway (e.g., Dkk1), while 16 pathways were for downregulated DEGs, including basal cell carcinoma (e.g., Lef1) (Table 2).

Table 1 Top 15 upregulated and downregulated genes differentially expressed between Pth1r knockout osteosarcoma cells and control

\begin{tabular}{|c|c|c|c|}
\hline Expression & Gene_Symbol & LogFC & Adjusted $p$ value \\
\hline \multirow[t]{14}{*}{ Upregulated } & Grin2c & 2.272 & 4.27E-06 \\
\hline & Ccnb3 & 3.243 & 4.27E-06 \\
\hline & Usp51 & 1.702 & 4.45E-06 \\
\hline & Slc1a3 & 1.443 & $6.34 \mathrm{E}-06$ \\
\hline & Kcnk1 & 2.774 & $6.34 \mathrm{E}-06$ \\
\hline & Bmp3 & 2.764 & $9.74 \mathrm{E}-06$ \\
\hline & $\mathrm{Rbm} 44$ & 1.846 & 1.14E-05 \\
\hline & Plppr5 & 2.010 & $1.85 \mathrm{E}-05$ \\
\hline & Phex & 1.977 & 1.85E-05 \\
\hline & Nell1 & 2.368 & $2.00 \mathrm{E}-05$ \\
\hline & Al593442 & 1.477 & $2.00 \mathrm{E}-05$ \\
\hline & Ooep & 0.828 & $2.00 \mathrm{E}-05$ \\
\hline & Trpc6 & 1.628 & $2.00 \mathrm{E}-05$ \\
\hline & Dkk1 & 1.730 & $2.00 \mathrm{E}-05$ \\
\hline \multirow[t]{14}{*}{ Downregulated } & Lef1 & -1.677 & $2.90 \mathrm{E}-06$ \\
\hline & Elf1 & -1.300 & 4.79E-06 \\
\hline & Jph1 & -1.674 & $5.47 \mathrm{E}-06$ \\
\hline & Zfhx4 & -2.183 & $6.34 \mathrm{E}-06$ \\
\hline & S1pr3 & -1.209 & $8.30 \mathrm{E}-06$ \\
\hline & Slc20a2 & -1.031 & $9.06 \mathrm{E}-06$ \\
\hline & Pdgfc & -1.073 & $9.20 \mathrm{E}-06$ \\
\hline & Wbp4 & -1.221 & $9.74 \mathrm{E}-06$ \\
\hline & Robol & -1.536 & $1.12 \mathrm{E}-05$ \\
\hline & Dgkh & -1.183 & $1.12 \mathrm{E}-05$ \\
\hline & Mpped2 & -1.873 & $1.14 \mathrm{E}-05$ \\
\hline & Dnajc15 & -1.661 & $1.24 \mathrm{E}-05$ \\
\hline & Atp10a & -1.118 & $1.85 \mathrm{E}-05$ \\
\hline & Slc6a15 & -2.051 & $1.85 E-05$ \\
\hline
\end{tabular}

FC fold change, adjusted $p$ value the $p$ value was corrected with the BenjaminiHochberg $(\mathrm{BH})$ algorithm
In addition, several GO terms, including 909 biological process (GO-BP), 63 cellular component (GO-CC), and 109 molecular function (GO-MF) categories were also enriched for upregulated DEGs, while 578 GO-BP, 42 GO-CC, and 48 GO-MF categories were for downregulated DEGs. To simplify the results, only the GO terms containing PTHR1 gene was displayed in this study (Fig. 1) because no KEGG pathway was obtained for PTHR1 gene. As expected, PTHR1 was found to be involved in cell proliferation process.

\section{PPI network construction}

A PPI network, including 534 nodes and 2830 edges (interaction relationships), was constructed after mapping the DEGs into the PPI data (Fig. 2; Additional file 1). By calculating the degree, betweenness, and closeness centrality, Agt gene was found to be the most key hub gene (Table 3). More interestingly, Agt was shown to interact with PTHR1 in PPI network, further indicating PTHR1 may promote the development of OS by influencing the expression of this gene. The importance of this gene was also confirmed in the module analysis (Fig. 3). Five modules were screened according to the given parameters (Table 4), among which module 1 (including Agt) was considered as the most significant with MCODE score $=8$ and nodes $=17$. Function enrichment analysis of module 1 (Table 2) showed chemokine- and cytokine-related inflammation pathways may be crucial, in which all enriched genes (CCR5, CXCL13, GNAI1, CCR3, CCR2, CCL9) could interact with Agt gene (Fig. 3; Additional file 1), indirectly illustrating the important role of Agt in OS.

\section{Discussion}

Using the microarray data of OS provided by Ho et al. [8], we found PTHR1 knockdown could induce the upregulation of Dkk1, but the downregulation of Lef1. Dkk1 is thought to act as a soluble inhibitor for Wnt signaling [21], while transcription factor Lef1 mediates Wnt signaling pathway by binding with its co-activator $\beta$-catenin [22]. Several studies have demonstrated that activation of Wnt signaling promotes OS cell proliferation and invasion [23], but contrast results can be obtained after its inhibition [24, 25]. Accordingly, we believe Wnt pathway genes (Dkk1 and Lef1) may be an important downstream targets for PTHR1 to participate in the proliferation and invasion of OS, which was also identified in the study of Ho et al. [8]. Although accumulating evidence has confirmed the high expression of Lef1 regulates cell proliferation, migration, invasion, and cancer stem-like cell self-renewal, leading to poor prognosis of patients [26, 27], their roles in OS remain rarely reported, and thus, this gene may be a new target for further exploration. The role of Dkk1 in OS remains still 
Table 2 KEGG pathway enrichment of all DEGs and modules

\begin{tabular}{|c|c|c|c|c|c|}
\hline DEGs & Expression & Term & Count & $p$ value & Genes \\
\hline \multirow[t]{31}{*}{ All } & \multirow[t]{24}{*}{ Upregulated } & $\begin{array}{l}\text { mmu05150:Staphylococcus } \\
\text { aureus infection }\end{array}$ & 13 & $1.16 \mathrm{E}-08$ & $\begin{array}{l}\text { C1qa, C3ar1, C1qb, Selp, Fcgr2b, } \\
\text { C4b, Fcgr4, H2-aa, Cfd, H2-ea.-ps... }\end{array}$ \\
\hline & & mmu05152:Tuberculosis & 16 & $1.64 \mathrm{E}-04$ & $\begin{array}{l}\text { Mrc1, Cd209a, Tlr1, Fcgr4, Ctss, } \\
\text { Tlr9, Fcgr3, Vdr, Fcgr2b, Mapk13... }\end{array}$ \\
\hline & & mmu03320:PPAR signaling pathway & 10 & 4.65E-04 & $\begin{array}{l}\text { Lpl, Cd36, Cyp27a1, Pparg, Fabp4, } \\
\text { Aqp7, Fabp7, Adipoq, Acsl6, Angptl4 }\end{array}$ \\
\hline & & mmu04145:Phagosome & 15 & 4.89E-04 & $\begin{array}{l}\text { Mrc1, H2-m9, Cd209a, Fcgr4, Ctss, } \\
\text { Fcgr3, Cybb, Cd36, H2-m11, Fcgr2b... }\end{array}$ \\
\hline & & $\begin{array}{l}\text { mmu04610:Complement and } \\
\text { coagulation cascades }\end{array}$ & 9 & 0.001 & $\begin{array}{l}\text { C1qa, C3ar1, C1qb, C4b, Cd59a, } \\
\text { F3, F8, Cfd, C1qc }\end{array}$ \\
\hline & & $\begin{array}{l}\text { mmu04620:Toll-like receptor } \\
\text { signaling pathway }\end{array}$ & 10 & 0.002 & $\begin{array}{l}\text { Cd86, Ccl3, Mapk13, Irf7, Tlr1, II12a, } \\
\text { Ticam2, Trr7, TIr8, TIr9 }\end{array}$ \\
\hline & & $\begin{array}{l}\text { mmu04514:Cell adhesion } \\
\text { molecules (CAMs) }\end{array}$ & 13 & 0.002 & $\begin{array}{l}\text { Selp, H2-m9, Cadm1, Neo1, Ncam1, } \\
\text { Siglec1, Cd86, H2-m11, H2-aa, Cd4... }\end{array}$ \\
\hline & & $\begin{array}{l}\text { mmu04614:Renin-angiotensin } \\
\text { system }\end{array}$ & 6 & 0.003 & Ace, Agtr1a, Agt, Prcp, Cpa3, Enpep \\
\hline & & $\begin{array}{l}\text { mmu04080:Neuroactive } \\
\text { ligand-receptor interaction }\end{array}$ & 18 & 0.004 & $\begin{array}{l}\text { C3ar1, Thrb, Grik2, Lpar3, Vipr2, Ednra, } \\
\text { P2ry13, Aplnr, P2ry6, Adrb2... }\end{array}$ \\
\hline & & mmu04924:Renin secretion & 8 & 0.004 & $\begin{array}{l}\text { Ednra, Ace, Adrb2, Agtr1a, Agt, } \\
\text { Pde1a, Pde3b, Cacna1d }\end{array}$ \\
\hline & & mmu05330:Allograft rejection & 7 & 0.005 & $\begin{array}{l}\text { H2-m9, Cd86, H2-m11, I112a, H2-aa, } \\
\mathrm{H} 2-\mathrm{t} 24, \mathrm{H} 2 \text {-ea-ps }\end{array}$ \\
\hline & & mmu04978:Mineral absorption & 6 & 0.006 & Vdr, Atp1b1, Mt2, Cybrd1, Slc40a1, Trf \\
\hline & & mmu04940:Type I diabetes mellitus & 7 & 0.009 & $\begin{array}{l}\text { H2-m9, Cd86, H2-m11, II12a, H2-aa, } \\
\text { H2-t24, H2-ea--ps }\end{array}$ \\
\hline & & $\begin{array}{l}\text { mmu05142:Chagas disease } \\
\text { (American trypanosomiasis) }\end{array}$ & 9 & 0.010 & $\begin{array}{l}\text { C1qa, C1qb, Ace, Ccl3, Mapk13, II12a, } \\
\text { Smad3, C1qc, Trr9 }\end{array}$ \\
\hline & & mmu05332:Graft-versus-host disease & 6 & 0.017 & $\begin{array}{l}\text { H2-m9, Cd86, H2-m11, H2-aa, } \\
\text { H2-t24, H2-ea.-ps }\end{array}$ \\
\hline & & mmu05133:Pertussis & 7 & 0.020 & $\begin{array}{l}\text { C1qa, C1qb, C4b, Mapk13, } \\
\text { Il12a, Ticam2, C1qc }\end{array}$ \\
\hline & & mmu04310:Wnt signaling pathway & 10 & 0.021 & $\begin{array}{l}\text { Fzd9, Dkk1, Sfrp1, Sfrp2, Fzd3, Camk2b, } \\
\text { Fzd5, Daam2, Lrp5, Fzd6 }\end{array}$ \\
\hline & & $\begin{array}{l}\text { mmu04060:Cytokine-cytokine } \\
\text { receptor interaction }\end{array}$ & 14 & 0.025 & $\begin{array}{l}\|11 r 2,\| 111, \text { Ccl3, Osmr, Ccl8, Pf4, Ccl7, } \\
\text { Tnfsf10, Ccr5, Cxcl13... }\end{array}$ \\
\hline & & $\begin{array}{l}\text { mmu04960:Aldosterone-regulated } \\
\text { sodium reabsorption }\end{array}$ & 5 & 0.027 & Atp1b1, Sgk1, Nr3c2, Igf1, Insr \\
\hline & & mmu04380:Osteoclast differentiation & 9 & 0.029 & $\begin{array}{l}\text { I1r1, Cybb, Fcgr2b, Mapk13, Pparg, } \\
\text { Fcgr4, Fhl2, Trem2, Fcgr3 }\end{array}$ \\
\hline & & $\begin{array}{l}\text { mmu04612:Antigen processing } \\
\text { and presentation }\end{array}$ & 7 & 0.031 & $\begin{array}{l}\mathrm{H} 2 \text {-m9, H2-m11, H2-aa, Cd4, } \\
\mathrm{Ctss}, \mathrm{H} 2 \text { - } 24 \text { 24, H2-ea.-ps }\end{array}$ \\
\hline & & $\begin{array}{l}\text { mmu04640:Hematopoietic } \\
\text { cell lineage }\end{array}$ & 7 & 0.034 & $\begin{array}{l}\|112,\| 1 \mathrm{r} 1, \mathrm{Cd} 36, \mathrm{Cd} 59 \mathrm{a}, \\
\mathrm{Cd} 33, \mathrm{Csf3r}, \mathrm{Cd} 4\end{array}$ \\
\hline & & mmu05140:Leishmaniasis & 6 & 0.037 & $\begin{array}{l}\text { Mapk13, II12a, Fcgr4, H2-aa, } \\
\text { H2-ea.-ps, Fcgr3 }\end{array}$ \\
\hline & & mmu05144:Malaria & 5 & 0.049 & Selp, Cd36, II12a, Thbs4, Tlr9 \\
\hline & \multirow[t]{7}{*}{ Downregulated } & mmu01130:Biosynthesis of antibiotics & 22 & $3.33 \mathrm{E}-06$ & $\begin{array}{l}\text { Cyp51, Ldhb, Shmt2, Msmo1, Pfkl, } \\
\text { Hmgcr, Pafah2, Pgd, Pfkp, Fdps... }\end{array}$ \\
\hline & & mmu01100:Metabolic pathways & 63 & $2.00 E-04$ & $\begin{array}{l}\text { Ldhb, Sgms2, Alg1, Hmgcr, Cyp2s1, } \\
\text { Pgd, Cyp2j6, Pgam1, Lss, Hlcs... }\end{array}$ \\
\hline & & mmu00100:Steroid biosynthesis & 6 & $2.40 \mathrm{E}-04$ & Cyp51, Msmo1, Sqle, Lss, Dhcr24, Fdft1 \\
\hline & & $\begin{array}{l}\text { mmu05412:Arrhythmogenic right } \\
\text { ventricular cardiomyopathy (ARVC) }\end{array}$ & 10 & $3.55 \mathrm{E}-04$ & $\begin{array}{l}\text { Itga5, Lmna, Itga11, Cacnb2, Sgcd, } \\
\text { Actn1, Gja1, Lef1, Cacnb3, Sgcb }\end{array}$ \\
\hline & & mmu00010:Glycolysis/Gluconeogenesis & 9 & 0.001 & $\begin{array}{l}\text { Pgm2, Ldhb, Tpi1, Pfkl, Pfkp, Pgam1, } \\
\text { Adh7, Aldh3b1, Eno1 }\end{array}$ \\
\hline & & mmu00240:Pyrimidine metabolism & 10 & 0.005 & $\begin{array}{l}\text { Pold4, Umps, Pole2, Pold1, Cda, } \\
\text { Uck2, Dpyd, Polr3c, Nt5e, Polr2a }\end{array}$ \\
\hline & & mmu00230:Purine metabolism & 13 & 0.011 & $\begin{array}{l}\text { Ak4, Polr3c, Pfas, Polr2a, Pgm2, Pold4, } \\
\text { Pole2, Pde1c, Pold1, Pde5a... }\end{array}$ \\
\hline
\end{tabular}


Table 2 KEGG pathway enrichment of all DEGs and modules (Continued)

\begin{tabular}{|c|c|c|c|c|c|}
\hline DEGs & Expression & Term & Count & $p$ value & Genes \\
\hline & & $\begin{array}{l}\text { mmu05410:Hypertrophic } \\
\text { cardiomyopathy (HCM) }\end{array}$ & 8 & 0.012 & $\begin{array}{l}\text { Itga5, Tgfb3, Lmna, Itga11, } \\
\text { Cacnb2, Sgcd, Cacnb3, Sgcb }\end{array}$ \\
\hline & & $\begin{array}{l}\text { mmu00030:Pentose } \\
\text { phosphate pathway }\end{array}$ & 5 & 0.014 & Pgm2, Pfkl, Pgd, Pfkp, Dera \\
\hline & & $\begin{array}{l}\text { mmu05414:Dilated } \\
\text { cardiomyopathy }\end{array}$ & 8 & 0.015 & $\begin{array}{l}\text { Itga5, Tgfb3, Lmna, Itga1 1, } \\
\text { Cacnb2, Sgcd, Cacnb3, Sgcb }\end{array}$ \\
\hline & & $\begin{array}{l}\text { mmu00670:One carbon } \\
\text { pool by folate }\end{array}$ & 4 & 0.021 & Mthfd1, Shmt2, Aldh1l1, Mthfd1l \\
\hline & & $\begin{array}{l}\text { mmu00051:Fructose and } \\
\text { mannose metabolism }\end{array}$ & 5 & 0.021 & Akr1b8, Tpi1, Pfkl, Pfkp, Pmm2 \\
\hline & & mmu05217:Basal cell carcinoma & 6 & 0.029 & Wnt4, Fzd1, Lef1, Ptch2, Axin2, Gli3 \\
\hline & & mmu01200:Carbon metabolism & 9 & 0.030 & $\begin{array}{l}\text { Tpi1, Shmt2, Pfkl, Pgd, Phgdh, } \\
\text { Pfkp, Esd, Pgam1, Eno1 }\end{array}$ \\
\hline & & $\begin{array}{l}\text { mmu00900:Terpenoid } \\
\text { backbone biosynthesis }\end{array}$ & 4 & 0.034 & Hmgcr, Fdps, Hmgcs1, Idi1 \\
\hline & & $\begin{array}{l}\text { mmu01230:Biosynthesis } \\
\text { of amino acids }\end{array}$ & 7 & 0.036 & $\begin{array}{l}\text { Tpi1, Shmt2, Pfkl, Phgdh, } \\
\text { Pfkp, Pgam1, Eno1 }\end{array}$ \\
\hline \multirow[t]{4}{*}{ Module } & 1 & $\begin{array}{l}\text { mmu04062:Chemokine } \\
\text { signaling pathway }\end{array}$ & 6 & $1.70 \mathrm{E}-05$ & $\begin{array}{l}\text { CCR5, CXCL13, GNAl1, } \\
\text { CCR3, CCR2, CCL9 }\end{array}$ \\
\hline & & $\begin{array}{l}\text { mmu04080:Neuroactive } \\
\text { ligand-receptor interaction }\end{array}$ & 6 & $1.00 \mathrm{E}-04$ & $\begin{array}{l}\text { C3AR1, APLNR, P2RY13, } \\
\text { S1PR3, HTR1B, LPAR3 }\end{array}$ \\
\hline & & $\begin{array}{l}\text { mmu04060:Cytokine-cytokine } \\
\text { receptor interaction }\end{array}$ & 4 & $8.90 \mathrm{E}-03$ & CCR5, CXCL13, CCR3, CCR2 \\
\hline & & $\begin{array}{l}\text { mmu04024:CAMP } \\
\text { signaling pathway }\end{array}$ & 3 & $4.80 \mathrm{E}-02$ & HTR1B, GNAI1, HCAR1 \\
\hline
\end{tabular}

DEGs differentially expressed genes

controversial. In contrast to the theoretical expectation $[28,29]$, as well as our result (lower expression in OS), some scholars recently have identified the elevated expression of Dkk1 in OS tissues and cells $[30,31]$ and blockage of Dkk1 via a monoclonal antibody inhibits OS metastasis [32]. This indicates DKK1 represents a class of Janus-faced molecules with dichotomous roles in OS. We hypothesize the underlying mechanisms may be related with the status of p53 in OS. It has been reported that Dkk-1 can be induced by wild-type p53, but not by mutant p53 (R249S) [33]. Thus, the downregulation of p53 in OS with wild-type p53 may lead to the lower expression of Dkk-1, while Dkk-1 may be increased in a p53-independent manner for OS initiation and maintenance when p53 mutant occurs, which is similar to the regulatory mechanism between $\mathrm{p} 53$ and p21 in cancer [34]. Also, a recent study indicates exogenous introduction of p53 and Dkk1 could obviously inhibit the growth of OS cells, cause the cell cycle arrest at G0/G1 phase and apoptosis of OS cells compared with Dkk1 and p53 alone [35], further predicting a synergic relation between p53 and Dkk1. Zhang et al. further found the antiproliferative effects of ursolic acid in OS cells may be mediated by upregulating p53 and then inhibit Wnt/ $\mathrm{\beta}$ catenin signaling [25]. In addition, p53 loss is observed to activate PTHrP-cAMP-CREB1 signaling [11] which is the downstream molecule of PTHR1 and thus may downregulate Dkk1 for OS as our study reported. However, further studies are also needed to confirm this mechanism of p53-PTHR1-Dkk1 in OS.

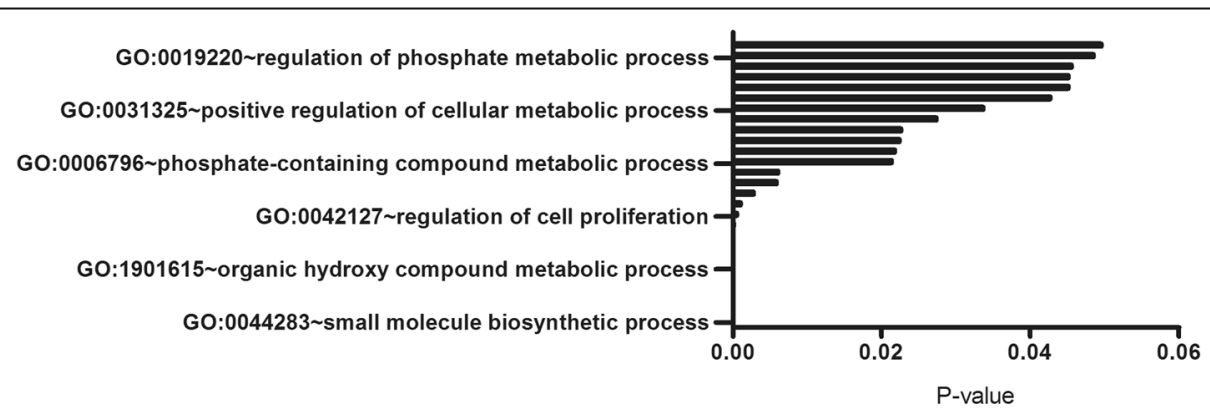

Fig. 1 PTH1R enriched gene ontology (GO) terms for biological processes. Cell proliferation process was enriched 


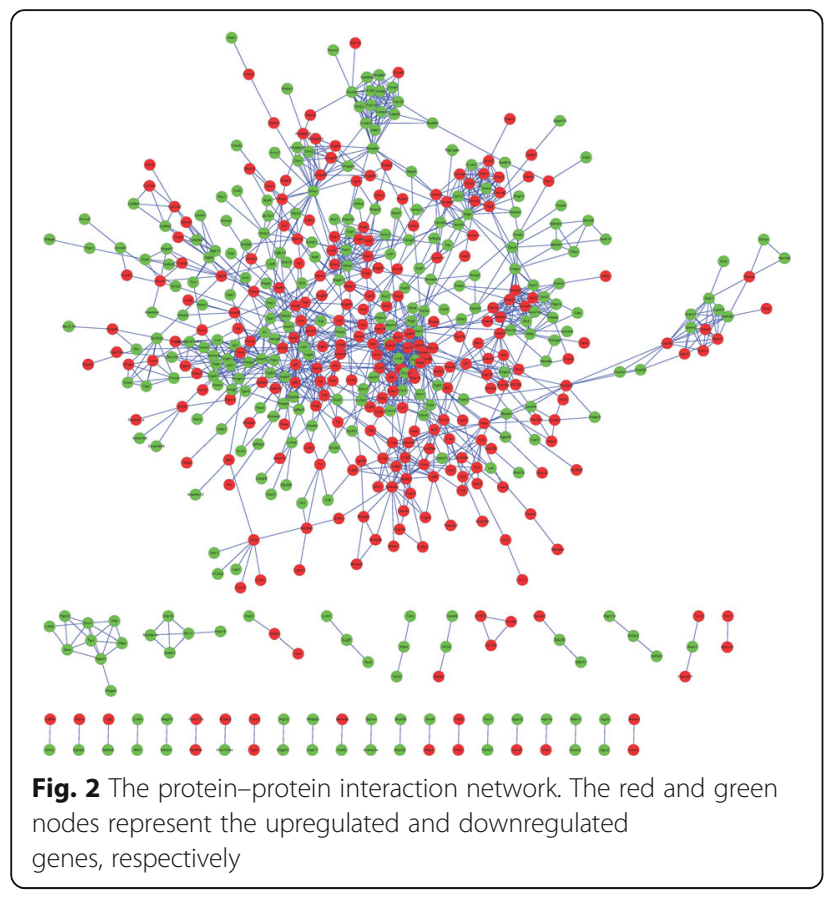

Table 3 Hub genes in the protein-protein interaction network

\begin{tabular}{|c|c|c|c|c|c|}
\hline Gene & Degree & Gene & Betweenness & Gene & Closeness \\
\hline Agt & 39 & Agt & $13,427.92$ & Agt & $2.21 \mathrm{E}-05$ \\
\hline Lpar3 & 26 & $\mathrm{Ar}$ & 8585.025 & Srebf1 & $2.21 \mathrm{E}-05$ \\
\hline Gnai1 & 25 & Pla2g2d & 8001.098 & Ccr2 & $2.21 \mathrm{E}-05$ \\
\hline Ccr5 & 24 & Srebf1 & 7904.877 & Ccr5 & $2.21 \mathrm{E}-05$ \\
\hline Ccla & 24 & Pax6 & 7664.532 & Lpar3 & $2.21 \mathrm{E}-05$ \\
\hline $\mathrm{Ccr} 2$ & 23 & Rhoc & 7643.579 & Gnai1 & $2.21 \mathrm{E}-05$ \\
\hline $\mathrm{Ccr3}$ & 22 & Dlg4 & 6747.256 & Ptafr & $2.21 \mathrm{E}-05$ \\
\hline lgf1 & 21 & Actn1 & 6420.109 & Igf1 & $2.21 \mathrm{E}-05$ \\
\hline Entpd1 & 20 & Gnai1 & 6334.163 & $\mathrm{Ar}$ & $2.21 \mathrm{E}-05$ \\
\hline Rhoc & 20 & Igf1 & 5806.686 & $\mathrm{Ccr3}$ & $2.20 \mathrm{E}-05$ \\
\hline Dlg4 & 19 & Racgap1 & 5675.621 & Ccl9 & $2.20 \mathrm{E}-05$ \\
\hline Entpd3 & 19 & Cyp2e1 & 5666.956 & P2ry 12 & $2.20 \mathrm{E}-05$ \\
\hline C3ar1 & 19 & Lpar3 & 5255.704 & Aplnr & $2.20 \mathrm{E}-05$ \\
\hline $\operatorname{Ar}$ & 19 & Gpc6 & 5126.2 & C3ar1 & $2.20 \mathrm{E}-05$ \\
\hline Dlg3 & 18 & Tgfb3 & 5025.73 & $\mathrm{Htr} 2 \mathrm{a}$ & $2.20 \mathrm{E}-05$ \\
\hline P2ry12 & 17 & $\mathrm{H} 2-\mathrm{Aa}$ & 4732.818 & Pparg & $2.20 \mathrm{E}-05$ \\
\hline $\mathrm{Htr} 1 \mathrm{~b}$ & 17 & Pld4 & 4646.952 & Abca1 & 2.20E-05 \\
\hline Aplnr & 17 & Entpd1 & 4307.738 & $\mathrm{Cd} 36$ & 2.20E-05 \\
\hline Srebf1 & 17 & $\mathrm{Htr} 2 \mathrm{a}$ & 4269.31 & Pf4 & $2.20 \mathrm{E}-05$ \\
\hline Aurkb & 16 & Ctss & 4234.501 & Agtr1a & $2.20 \mathrm{E}-05$ \\
\hline
\end{tabular}

Degree the number of interactions per node (protein), betweenness the number of shortest paths that pass through each node, closeness centrality the average length of the shortest paths to access all other proteins in the network

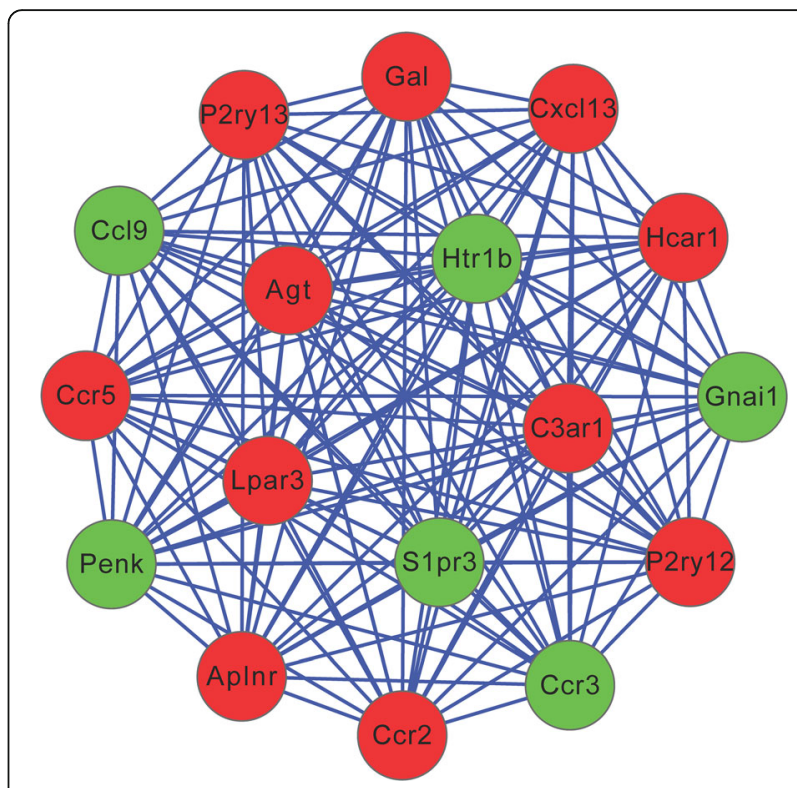

Fig. 3 The most significant module extracted from protein-protein interaction network. The red and green nodes represent the upregulated and downregulated genes, respectively

Furthermore, Agt was also shown to be upregulated after PTHR1 silencing. More interestingly, it could interact with PTHR1 in PPI network, indicating the change in its expression may be a crucial mechanism for explaining the roles of PTHR1 in OS, which was first identified in our study. Function enrichment analysis proved Agt may be involved in Renin-angiotensin system. As is well known, angiogenesis is an indispensable process for tumor growth and metastatic dissemination via providing essential oxygen and nutrients to proliferating cells and then a route for metastasis delivery [36]. Thus, targeted inhibition of angiogenesis may be potential approaches for prevention of OS progression. AGT, encoded by Agt gene, is a 452-amino-acid-residue protein that can be cleaved by renin to generate angiotensin I (AngI) which has been demonstrated to exert antiangiogenic properties in vitro and in vivo [37], suggesting the underlying anti-tumor activity of AGT. This conclusion has been further verified by recent studies. For example, Bouquet et al. showed adenovirus-mediated Agt overexpression inhibited tumor growth in preestablished human MDAMB-231 mammary carcinomas in nude mice compared to controls and blocked tumorigenicity and pulmonary metastases of MDA-MB-231 and murine melanoma B16F10 cells when they were injected into C57BL/6 mice [38]. Vincent et al. revealed mice with bitransgenic HCC (hepatocellular carcinoma)/Hu-AGT-TG exhibited a significantly longer survival time than the HCC-TG mice and a decrease in both tumor growth and blood flow velocities of the liver through reducing of endothelial arterial markers (active Notch4, Delta-like 4 ligand and ephrin B2) [39]. However, the mechanism of Agt gene in OS remains unclear. In this 
Table 4 Module analysis

\begin{tabular}{|c|c|c|c|c|}
\hline Cluster & $\begin{array}{l}\text { Score } \\
\text { (Density } \times \\
\text { number of Nodes) }\end{array}$ & Nodes & Edges & Node IDs \\
\hline 1 & 8 & 17 & 136 & Hcar1, Agt, Ccr2, Lpar3, Ccr5, Ccr3, Gnai1, P2ry12, P2ry13, S1 pr3, C3ar1, Cc19, Cxcl13, Aplnr, Penk, Gal, Htr1b \\
\hline 2 & 4.75 & 20 & 95 & $\begin{array}{l}\text { Cacng5, Agtr1a, Ednra, Lpar6, Gpr65, P2ry6, Ptafr, Ptgfr, Htr2a, Dlg4, Grin2c, Gria2, Grik2, Gria4, Dlg3, } \\
\text { Cpt1c, Cacng7, Olfm1, Olfm2, Cnih2 }\end{array}$ \\
\hline 3 & 4.667 & 12 & 56 & Rangap1, Ccnb1, Cdc20, Kif23, Racgap1, Cdca8, Aurkb, Kif2c, Cenpe, Cenph, Cenpp, Nde1 \\
\hline 4 & 4.4 & 10 & 44 & Srebf2, Lss, Cyp51, Msmo1, Hmgcs1, Hmgcr, Sqle, Fdft1, Idi1, Fdps \\
\hline 5 & 4 & 9 & 36 & Actn1, Igf1, Igf2, Vegfc, Tgfb3, Cfd, Pf4, Srgn, F8 \\
\hline
\end{tabular}

study, we also predicted Agt might exert anti-malignancy effects by interacting with inflammation-related genes (such as CCR3, CC chemokine receptor 3; and CCL9, chemokine $\mathrm{CC}$ chemokine ligand 9). The relationship between inflammation genes and cancer development has been extensively studied. For example, it has been reported that CCR3 is highly expressed in breast cancer samples, especially luminal-like subtype [40]. Knockdown of CCR3 inhibited cellular proliferation, invasion, and migration, which was ERK signaling pathway-dependent [41, 42]. CCL9 was also shown to be highly induced in Gr-1 + CD11b + immature myeloid cells and premetastatic lung of tumor-bearing mice. Knockdown of CCL9 in myeloid cells reduced tumor cell proliferation and metastasis [43].

\section{Conclusion}

Our present study preliminarily reveals PTHR1 may play important roles in the development and progression of OS by activating Wnt (Dkk1 and Lef1), angiogenesis, and inflammation pathways (Agt-CCR3 and Agt-CCL9). Lef1, Agt, CCR3, and CCL9 are all underlying new targets because no studies focused on them in OS. Thus, further in vitro and in vivo experimental studies were necessary to confirm the above findings. In addition, the role of Dkk1 is controversial and whether its expression is dependent on p53 status in OS also needs further investigation.

\section{Additional file}

Additional file 1: PPI network construction. (TSV 148kb)

\section{Abbreviations}

Agt: Angiotensinogen; Angl: Angiotensin I; BH: Benjamini-Hochberg; BP: Biological processes; CC: Cellular component; CCL9: Chemokine CC chemokine ligand 9; CCR3: CC chemokine receptor 3; CREB: CAMP-response element binding protein; CTGF: Connective tissue growth factor; DAVID: Database for Annotation, Visualization and Integrated Discovery; DEGs: Differentially expressed genes; Dkk1: Dickkopf-related protein 1; FGF2: Fibroblast growth factor 2; GO: Gene Ontology; HAS2: HA-synthase-2; HCC: Hepatocellular carcinoma; KEGG: Kyoto encyclopedia of genes and genomes; Lef1: Lymphoid enhancer-binding factor 1; LIMMA: Linear Models for Microarray data; MCODE: Molecular Complex Detection; MF: Molecular function; OS: Osteosarcoma; PPI: Protein-protein interaction; PTH: Parathyroid hormone; PTHR1: Parathyroid hormone type 1 receptor; PTHrP: Parathyroid hormone-related peptide; RMA: Robust Multichip Average; Runx-2: Runt- related transcription factor 2; STRING: Search Tool for the Retrieval of Interacting Genes; TGF-b1: Transforming growth factor b1

\section{Acknowledgements}

We thank the generous support by the Liaoning Cancer Hospital \& Institute (Shenyang) and Dalian Municipal Central Hospital Affiliated of Dalian Medical University (Dalian).

We thank Guanying Liu for her numerous constructive comments in the process of writing this manuscript.

\section{Funding}

None.

Availability of data and materials

The microarray data GSE46861 were downloaded from the GEO database in NCBI (http://www.ncbi.nlm.nih.gov/geo/).

\section{Authors' contributions}

SLL and XJZ participated in the design of this study. SLL and ZW collected important background information and data. SLL and KW performed the statistical and bioinformatics analyses. SLL and YJD drafted the manuscript. All authors read and approved the final manuscript.

\section{Ethics approval}

This article does not contain any studies with human participants or animals performed by any of the authors.

As the data used in this study was downloaded from GEO database and no human experiment was involved in this study, there was no informed consent.

\section{Consent for publication}

Not applicable.

\section{Competing interests}

The authors declare that they have no competing interest.

\section{Publisher's Note}

Springer Nature remains neutral with regard to jurisdictional claims in published maps and institutional affiliations.

\section{Author details}

${ }^{1}$ Department of Bone and Soft Tissue Tumor Surgery, Cancer Hospital of China Medical University, Liaoning Cancer Hospital \& Institute, 44, Xiaoheyan Road, Dadong District, Shenyang, Liaoning 110042, China. ²Department of Hand and Foot Surgery, Dalian Municipal Central Hospital Affiliated of Dalian Medical University, Dalian, Liaoning 116033, China. ${ }^{3}$ Molecular Pathology Testing Center, Foshan Chancheng Central Hospital, Foshan, Guangdong 528031, China. ${ }^{4}$ Department of Orthopedics, Zhongshan Hospital Affiliated to Fudan University, Shanghai 200032, China. 
Received: 3 June 2017 Accepted: 23 October 2017

Published online: 09 November 2017

\section{References}

1. Berner K, Johannesen TB, Berner A, Haugland HK, Bjerkehagen B, Bøhler PJ, et al. Time-trends on incidence and survival in a nationwide and unselected cohort of patients with skeletal osteosarcoma. Acta Oncol. 2015;54:25-33.

2. Moreno F, Cacciavillano W, Cipolla M, Coirini M, Streitenberger P, López MJ, et al. Childhood osteosarcoma: incidence and survival in Argentina. Report from the National Pediatric Cancer Registry, ROHA Network 2000-2013. Pediatr Blood Cancer. 2017:64:e26533.

3. Yang R, Hoang BH, Kubo T, Kawano H, Chou A, Sowers R, et al. Overexpression of parathyroid hormone type 1 receptor confers an aggressive phenotype in osteosarcoma. Int J Cancer. 2007;121:943-54.

4. Alokail MS, Peddie MJ. Quantitative comparison of PTH1R in breast cancer MCF7 and osteosarcoma SaOS-2 cell lines. Cell Biochem Funct. 2008:26:522-33.

5. Avnet S, Longhi A, Salerno M, Halleen JM, Perut F, Granchi D, et al. Increased osteoclast activity is associated with aggressiveness of osteosarcoma. Int J Oncol. 2008;33:1231-8.

6. Lupp A, Klenk C, Röcken C, Evert M, Mawrin C, Schulz S. Immunohistochemical identification of the PTHR1 parathyroid hormone receptor in normal and neoplastic human tissues. Eur J Endocrino. 2010;162:979-86.

7. Ho PW, Russell M, Goradia A, Chalk A, Slavin J, Dickins R, et al. Abstract A54: PTHR1 signaling regulates the invasion and differentiation stage of osteosarcoma. Cancer Res. 2014;74:A54.

8. Ho PW, Goradia A, Russell MR, Chalk AM, Milley KM, Baker EK, et al. Knockdown of PTHR1 in osteosarcoma cells decreases invasion and growth and increases tumor differentiation in vivo. Oncogene. 2014;34:2922-33.

9. Walkley CR, Walia MK, Ho PW, Martin TJ. PTHrP, its receptor, and protein kinase A activation in osteosarcoma. Mol Cell Oncol. 2014;1:e965624.

10. Nikitovic D, Kavasi RM, Berdiaki A, Papachristou DJ, Tsiaoussis J, Spandidos DA, et al. Parathyroid hormone/parathyroid hormone-related peptide regulate osteosarcoma cell functions: focus on the extracellular matrix (review). Oncol Rep. 2016;36:1787-92

11. Walia MK, Ho PM, Taylor S, Ng AJ, Gupte A, Chalk AM, et al. Activation of PTHrP-CAMP-CREB1 signaling following p53 loss is essential for osteosarcoma initiation and maintenance. elife. 2016:5.

12. Datsis GA, Berdiaki A, Nikitovic D, Mytilineou M, Katonis $P$, Karamanos NK, et al. Parathyroid hormone affects the fibroblast growth factor-proteoglycan signaling axis to regulate osteosarcoma cell migration. FEBS J. 2011;278:3782-92.

13. Berdiaki A, Datsis GA, Nikitovic D, Tsatsakis A, Katonis P, Karamanos NK, et al. Parathyroid hormone (PTH) peptides through the regulation of hyaluronan metabolism affect osteosarcoma cell migration. IUBMB Life. 2010;62:377-86.

14. Irizarry RA, Hobbs B, Collin F, Beazer-Barclay YD, Antonellis KJ, Scherf U, et al. Exploration, normalization, and summaries of high density oligonucleotide array probe level data. Biostatistics. 2003:4:249-64.

15. Ritchie ME, Phipson B, Wu D, Hu Y, Law CW, Shi W, et al. LIMMA powers differential expression analyses for RNA-sequencing and microarray studies. Nucleic Acids Res. 2015;43:e47.

16. Kim Kl, van de Wiel MA. Effects of dependence in high-dimensional multiple testing problems. BMC Bioinformatics. 2008;9:114.

17. Szklarczyk D, Franceschini A, Wyder S, Forslund K, Heller D, Huerta-Cepas J, et al. STRING v10: protein-protein interaction networks, integrated over the tree of life. Nucleic Acids Res. 2015:43:D447-52.

18. Kohl M, Wiese S, Warscheid B. Cytoscape: software for visualization and analysis of biological networks. Methods Mol Biol. 2011;696:291-303.

19. Tang Y, Li M, Wang J, Pan Y, Wu FX. CytoNCA: a cytoscape plugin for centrality analysis and evaluation of protein interaction networks. Biosystems. 2015;127:67-72.

20. Bader GD, Hogue CW. An automated method for finding molecular complexes in large protein interaction networks. BMC Bioinformatics. 2003:4:2

21. Khalili S, Rasaee MJ, Bamdad T. 3D structure of DKK1 indicates its involvement in both canonical and non-canonical Wnt pathways. Mol Biol. 2017:51:180-92.

22. Zhou AD, Diao LT, Xu H, Xiao ZD, Li JH, Zhou H, et al. $\beta$-catenin/LEF1 transactivates the microRNA-371-373 cluster that modulates the Wnt/ $\beta$ catenin-signaling pathway. Oncogene. 2012;31:2968-78.

23. Xiao Q, Yang Y, Zhang X, An Q. Enhanced Wnt signaling by methylationmediated loss of SFRP2 promotes osteosarcoma cell invasion. Tumour Biol. 2016;37:6315-21.
24. Liu X, Li L, Lv L, Chen D, Shen L, Xie Z. Apigenin inhibits the proliferation and invasion of osteosarcoma cells by suppressing the Wnt/ $\beta$-catenin signaling pathway. Oncol Rep. 2015;34:1035-41.

25. Zhang RX, Li Y, Tian DD, Liu Y, Nian W, Zou X, et al. Ursolic acid inhibits proliferation and induces apoptosis by inactivating Wnt/ $\beta$-catenin signaling in human osteosarcoma cells. Int J Oncol. 2016:49:1973-82.

26. Wang WJ, Yao Y, Jiang LL, Hu TH, Ma JQ, Ruan ZP, Tian T, Guo H, Wang SH, Nan KJ. Increased LEF1 expression and decreased Notch2 expression are strong predictors of poor outcomes in colorectal cancer patients. Dis Markers. 2013;35:395-405.

27. Gao X, Mi Y, Ma Y, Jin W. LEF1 regulates glioblastoma cell proliferation, migration, invasion, and cancer stem-like cell self-renewal. Tumour Biol. 2014:35:11505-11.

28. Yong WC, Kim TH, Jeong SH, Han JH, Park JS. Strong immunoexpression of Dickkopf-1 is associated with response to bortezomib in multiple myeloma. Blood. 2016;128:3270.

29. Liu Y, Liu YZ, Zhang RX, Wang X, Meng ZJ, Huang J, et al. Oridonin inhibits the proliferation of human osteosarcoma cells by suppressing Wnt/ $\mathrm{B}$ catenin signaling. Int J Oncol. 2014;45:795-803.

30. Lee N, Smolarz AJ, Olson S, David O, Reiser J, Kutner R, et al. A potential role for Dkk-1 in the pathogenesis of osteosarcoma predicts novel diagnostic and treatment strategies. Br J Cancer. 2007:97:1552-9.

31. Chen C, Zhou H, Zhang X, Ma X, Liu Z, Liu X. Elevated levels of Dickkopf-1 are associated with $\beta$-catenin accumulation and poor prognosis in patients with chondrosarcoma. PLoS One. 2014;9:e105414.

32. Goldstein SD, Matteo T, Bautista GW, Masanori H, Loeb DM. A monoclonal antibody against the Wnt signaling inhibitor dickkopf-1 inhibits osteosarcoma metastasis in a preclinical model. Oncotarget. 2016;7:21114-23.

33. Wang J, Shou J, Chen X. Dickkopf-1, an inhibitor of the Wnt signaling pathway, is induced by p53. Oncogene. 2000;19:1843-8.

34. Galanos P, Vougas K, Walter D, Polyzos A, Mayamendoza A, Haagensen EJ, et al. Chronic p53-independent p21 expression causes genomic instability by deregulating replication licensing. Nat Cell Biol. 2016;18:777-89.

35. Gao F, Bi B, Liao G. Regulation of exogenous P53 combined with Dickkopf-1 on human osteosarcoma MG-63 cells. Int J Clin Exp Med. 2017:10:9252-8.

36. Wegmanostrosky $T$, Sotoreyes E, Vidalmillán S, Sánchezcorona J. The reninangiotensin system meets the hallmarks of cancer. J Renin-AngiotensinAldosterone Syst. 2015;16:227-33.

37. Célérier J, Cruz A, Lamandé N, Gasc JM, Corvol P. Angiotensinogen and its cleaved derivatives inhibit angiogenesis. Hypertension. 2002;39:224-8.

38. Bouquet C, Lamandé N, Brand M, Gasc JM, Jullienne B, Faure G, et al. Suppression of angiogenesis, tumor growth, and metastasis by adenovirusmediated gene transfer of human angiotensinogen. Mol Ther. 2006;14:175-82.

39. Vincent $\mathrm{F}$, Bonnin $\mathrm{P}$, Clemessy $\mathrm{M}$, Contrerès JO, Lamandé $\mathrm{N}$, Gasc JM, et al. Angiotensinogen delays angiogenesis and tumor growth of hepatocarcinoma in transgenic mice. Cancer Res. 2009:69:2853-60.

40. Gong DH, Fan L, Chen HY, Ding KF, Yu KD. Intratumoral expression of CCR3 in breast cancer is associated with improved relapse-free survival in luminallike disease. Oncotarget. 2016;7:28570-8.

41. Lee YS, Kim SY, Song SJ, Hong HK, Lee Y, Oh BY, et al. Crosstalk between CCL7 and CCR3 promotes metastasis of colon cancer cells via ERK-JNK signaling pathways. Oncotarget. 2016;7:36842-53.

42. Zhu F, Liu P, Li J, Zhang Y. Eotaxin-1 promotes prostate cancer cell invasion via activation of the CCR3-ERK pathway and upregulation of MMP-3 expression. Oncol Rep. 2014:31:2049-54.

43. Yan HH, Jiang J, Pang $Y$, Achyut BR, Lizardo $M$, et al. CCL9 induced by TGF- $\beta$ signaling in myeloid cells enhances tumor cell survival in the premetastatic organ. Cancer Res. 2015;75:5283-98. 